\title{
Community Resilience in Urban Plural Context: Assessing Challenges and Strategies in Times of Covid- 19 Pandemic
}

\author{
Laila Kholid Alfirdaus ${ }^{1}$, Dzunuwanus Ghulam Manar ${ }^{2}$, Teguh Yuwono ${ }^{3}$ \\ \{laila.alfirdaus@live.undip.ac.id ${ }^{1}$ \} \\ Universitas Diponegoro, Indonesia ${ }^{1,2,3}$
}

\begin{abstract}
Some cities in Indonesia are currently known to be prone to crisis due to Covid19 pandemic. Some of them are also known to be building resilience system in their urban management program. Meanwhile, as we might already be aware of, those cities are plural in terms of social differences and identities. As a matter of fact, the success of policies, as in urban resilience building, are dependent towards the involvement of community. Therefore, it is interesting to scrutinize how cities that are socially plural strive to manage pandemic crisis and risks in their regions? How are minority groups and poor people, who are usually more prone to the crisis, involved in the local government's urban resilience project? And, what kind of strategies does the government apply to integrate social inclusion in urban resilience policy? What alternatives does community build to support their collective resilience? This research is proposed to reveal this issue by studying the experiences of Semarang city, Central Java, Indonesia in terms of social structure, as well as risks in times of Covid-19 pandemic. This study is expected to identify the social complexities in urban resilience policy, as well as the strategies applied either by the government and community to cope with these situations.
\end{abstract}

Keywords: Urban Resilience, Pandemic, Crisis Governance, Social Inclusion

\section{Introduction}

Some cities in Southeast Asian countries are known to be prone to crisis, caused either by pandemic, natural disasters or climate change [1]. Some of them are also known to concerning on building resilience system in their urban management program to deal with the risks [1]. However, as community in those countries is not homogeneous, there is a crucial question to raise, "How does the government build and manage urban resilience system in the plural city population?"

As we are already aware of, cities in Indonesia are mostly heterogeneous and identical with the dichotomization of native and new comers in their social structures, and consist of various ethnicities and religious beliefs, which, most importantly, also prone to the issues of social integration and cohesiveness in community's daily relationships [2]. Building resilience system, therefore, is not an easy task, as resilience requires not only infrastructure, but more importantly the people, which means that the success of policies is dependent towards the involvement of community and their daily interrelationships [3]. 
Considering this, therefore, it is interesting to scrutinize how cities that are socially plural strive to manage pandemic-induced crisis in their regions? What challenges and difficulties that might arise in building city resilience within plural population?

Referring to Burayadi et al. [4], urban resilience is, "not only as the ability to "bounce back" but also to "bounce forward" and adapt, reconstituting themselves into functional units, as well as their ability to withstand unpredictable catastrophes". To make this definition clearer Kuhlicke, Kabisch, and Rink (in Burayadi et al. [4]) asserts that resilience includes the aspects of adaptability, learning and transformation in response to environmental change, international and national security, and growing economic turbulence.

As we know, research on resilience is growing responding to the rising hazards that hit the cities, including in Southeast Asian countries. However, discussions on challenges and difficulties in resilience building and governance in the plural urban context is still lacking. Therefore, the question on the involvement of minority groups, as well as poor minority people, who are usually more prone to crisis, in the local government's urban resilience project, remains unanswered.

Based on the above written research background, this research is trying to answer the questions of, "How is urban resilience built and governed in plural Semarang city?", "How do the governments integrate social complexities in their resilience system?", and, "What are the challenges and difficulties that exist in building and governing resilience in plural urban community?"

This research is focused on Semarang, the capital city of Central Java Province, Indonesia. The city has $1,674,358$ population with the total wide of $373,8 \mathrm{~km}^{2}$. Population density in Semarang is 4.780 per $\mathrm{km}^{2}$. Semarang is an industrial and trading areas, with the number of SMEs (small and medium enterprises) approximately is 75.000 .

Up to now, Semarang is listed as one of the regions in Indonesia that is affected most by Covid-19, signified by the fast-growing number and rate of infection per population. Industries and SMEs which rely on crowd's activities more or less are influential to the increasing risks of infectious disease's expansion.

Yet, Semarang city government with the support of Central Java Province has been amongst the pioneers in neighborhood-based resilience building since the initial period of Covid-19 spreading. "Jogo Tonggo" is the government engineered resilience system in times of pandemic. "Jogo Tonggo" means to empower society in neighborhood environment to build mutual sharing and caring.

Nevertheless, building such a social resilience system in the context of pandemic is never easy. Social and economic factors have been challenging factors in functioning "Jogo Tonggo" as mechanism to prevent Covid-19 infection expansion. As industrial and trading area, crowdbased activities are the key that is helpful for running local economy so far. Factories and traditional markets are Semarang's economic heart. Therefore, it is sensible if stay-at-home campaign through "Jogo Tonggo" is never easy to implement.

As such, this research aims to explain the building and governing of urban resilience in plural urban context. It also means to identify the integration of social complexities in urban resilience system. Finally, it is directed to reveal challenges and strategies in the building and governing of resilience system in plural urban community.

This research is meant to widen the perspectives in urban resilience studies from the political science's point of view. The issues of resilience have been the interests of scholars from multi-disciplinary fields, but those that are related to pandemic-induced crisis are still marginal. While frameworks on resilience are mostly built from applied science, as urban 
planning, economy, environmental studies, and geography, they are also hardly connected to pandemic context.

With the growing case of Covid-19 pandemic, scrutinizing how society forms and involved in resilience building becomes crucial, given the nature of the crisis that is potentially catch-all and non-discriminating. By focusing on social issues and complexities in community, that might be influential in the building of community resilience system, the discussions on urban resilience is hopefully deepened.

For practical purpose, this study is expected to enable policy makers to consider more social aspects in designing resilience system, so it is more comprehensive in terms of being resolutions for the rising risks of pandemic-induced crisis.

\section{Methodology}

This research uses qualitative methods in its approach. It applies case study. The location of the study is Semarang, Central, Indonesia. The decision to study the city is based on consideration that in terms of social structures Semarang can be said as plural. Most population are Moslem, and by ethnicity it is featured with Javanese, but there remain some minority groups, as Chinese, Indians and Arabians that live side by side in community.

By focusing on this city, it is expected that the analysis in terms of challenges and strategies in building resilience system can be conducted. In-depth interviews and direct observations are applied to collect data. Informants consist of local governments and local community from different ethnic and religious backgrounds. Field research has been conducted since May 2020 and is still progressing up the end of this year.

\section{Results and Discussion}

There have been some literatures that discuss urban resilience, which can be mapped as the following. The first is those that discuss the concept of resilience and its critiques as Montenegro [5], who define resilience as adaptability to socio-ecological system, Ribeiro and Gonçalves [6], who sees the growing importance of resilience given the more complex structure of urban life, Caputo at al. [7], who help us differentiate the category of resilience into engineering and ecological, and Meerow and Newell [8], who refuse to see resilience as neutral concept, and believe it as boldly containing politics, which further bring impact to justice and equity.

The second is those that discuss resilience in various policy contexts including resilience to terrorism, conflict, flood, energy, disaster, and climate change [9][10][11].

The third is those that discuss resilience from justice perspective, as Ratanawaraha [12] and Cutter, Ash and Emrich [13], who see resilience as a crucial means to measure, as well as promote, equality.

Based on the above-mentioned theoretical discussions, in this regard, social resilience as this paper means is the participation of public in reducing the impacts of Covid-19 in order to support social adaptability to the changes in public health, social and economy induced by Covid-19 pandemic. Covid-19, as many other unexpected hazards, never anticipated before, but brings significant changes to daily social life. Many experts even assert that things would never be the same again in the future. Therefore, this paper is aware that the pandemic context brings 
totally different natures of challenges for the government and society, as well as requires totally different approach in social resilience building. This paper tries to scrutinize this issue in the context of urban community, which is pointed as amongst the riskiest segments of society.

Among the existing literatures that discuss resilience, there are however limited ones that try to see resilience and resilience building within plural urban society in the pandemic context. Meanwhile, it is commonly perceived that the more plural a community the more challenging the governance of daily social relationships, and the more homework to do to succeed resilience building policy.

Based on the provisional finding of this research, it is identified that resilience in an urban plural community in the pandemic context poses different challenges as compared to the crises induced by the other sources of hazards, as pandemic means that everybody has a risk of being impacted. While in natural hazard-induced crisis not all people affected, so that the social support system derived from neighborhood relationship is more possible to mobilize, in pandemic-induced crisis it is not an easy task at all.

Unlike flood and earthquake, pandemic is caused by invisible virus. Therefore, it requires high awareness in order to get secured from infection risk. In addition, as pandemic is not locally limited like flood and earthquake, all people are prone to the virus infection risks and get economically impacted. Therefore, the challenges are bigger, and thus, scrutinizing strategies to deal with these challenges is important to further highlight the clearer picture of government and society's approach of coping with the pandemic challenges in order to enrich the existing studies on social resilience.

In the context of socio-cultural in Semarang, neighborhood is still counted important in social life. Javanese culture that values collectiveness is a crucial explanation to understand why Semarang people, despite its urban characteristics remains put neighborhood as important in their social life. This is part of explanations of why "Jogo Tonggo", a policy means to encourage neighborhood as the main locomotive for stay-at-home campaign, is chosen by the local government to cope with the new Corona virus's infection.

This paper, however, does not mean to assess the success or failure of "Jogo Tonggo" because Covid-19 pandemic is still happened, and efforts to encourage community's involvement in infection expansion is still undergoing. Yet, provisional view about the on-going program is unavoidable. This paper rather supposes to give a brief portrait on how "Jogo Tonggo" and the other means of social resilience building underwent in Semarang's daily politics.

Based on our provisional research finding, in the times of Covid-19 pandemic, resilience building mechanism can be said as partly functional and partly not. Social activities that relate directly to the government's policy can be said to relatively comply with the government's regulation of health protocols. This is for instance found in Posyandu, an abbreviation of Pos Pelayanan Terpadu, a government-promoted of community service for public health, especially for children and elderlies, and PKK or Program Kesejahteraan Keluarga, a social activity of woman citizen in neighborhood community that tries to support women and family's welfare through community's saving and credit. Posyandu and PKK activities are relatively manageable, so they comply with government's health protocol instruction.

In daily life, a more impactful approach that will help community reduce the risks of being infected by the new Corona virus seems to also be difficult to promote. As an urban area that relies its economy much on industries and trading, Semarang faces a crucial challenge of governing public activities, either in economic, social and cultural areas. Semarang has long been benefited from and relies much on crowd-based activities, a situation that is contradictory to the Covid-19 free requirement. Meanwhile, as we might know, public resources to support 
stay-at-home activities are limited. Government funding is not sufficient enough to provide foods, if stay-at-home is made obligatory. Given these complexities, allowing people to run their economy, while suggesting them for using face mask, periodically washing hand, and keeping distance, is unavoidable, although it is not clear if all these things are obeyed.

"Jogo Tonggo" as promoted by Central Java provincial government and supported by Semarang city government looks to simplify the idea of resilience. The policy tries to encourage stay-at-home activities during pandemic, by empowering neighborhood as the main locomotive of the movement. However, the policy looks to disregard the fact that people are facing economic decrease, and therefore, they need to keep running their business in order to survive. "Jogo Tonggo"'s most weakness is in the lack of government's concrete support for lay people to stay at home. As a result, likewise, lay people disregard "Jogo Tonggo" and keep running their daily activities, as going to traditional markets and running their small food shops.

Meanwhile, on the side of community, collective resilience has not been strongly built. People tend to be fragmented between those that support stay-at-home activities and physical distancing and those who refuse them. Somehow, instead of being the supporting system, neighborhood becomes another pressure for those who are willing to maintain the beings safe from the new Corona virus's infection. An informant said, "I was told paranoia because I prohibit my children to go outside and keep distancing when we are out of our home." Another informant said, "My neighbor told me the more I feel scared the more stressful I will, and thus the more prone I am to get sicked and infected. This is groundless, because staying at home does not mean to all to stay stressful. Sometimes, it might be boring, but I try to creatively maintain my family's mentality healthy."

Neighborhood pressure, nevertheless, is another picture of collectiveness demand among community members, in which people are expected to remain united, despite the risks of corona infection. Of course, this does not mean to blame people personally. Rather, it might be rooted from the long-planted understanding that collectiveness means togetherness. People might not mean to risk others but keeping distance and not together with their neighbors is simply not the idea what "collectiveness" means for society.

In community's residency, things are mixed. In housing complex, paid security personnel usually are provided to make sure those coming to the area obey health protocol. Social resilience is supported with a more ordered mechanism. Meanwhile, in kampung residency, things run a bit differently. There is no ordered security system, and the situations become a bit difficult to control. Mosques and the other religious venues still become the source of crowd. People still come for Jumah prayer. They also still conduct Qur'anic study in masses. As compared to the other religious institutions, mosques are a bit hard to manage, because praying and rituals in Muslim culture are not possible to conduct online. Some mosques try their best to apply health protocols, while others face difficulties to enact health disciplines.

As such, we can see that building social resilience is not an easy and simple task in the times of Covid-19 pandemic. The government faces challenges in building new understanding about what collectiveness is in pandemic crisis. Neighborhood that usually becomes the crucial locomotive of social resilience in the other adversary contexts, in pandemic crisis, it can be source for social pressure. Therefore, although community is an important part in succeeding the pandemic handling, it remains insufficient, as an effective governance remains in the hand of the government. 


\section{Conclusion}

From the above-mentioned explanation, we can see that social resilience in the times of Covid-19 pandemic requires different approach than those in the other hazardous contexts like in natural disasters. It faces challenges from different understanding about collectiveness, as pre-requisite for resilience building, and thus, demands policy makers to think of proper strategies of behavioral changes.

\section{Acknowledgement}

Authors would like to express thankfulness to Faculty of Social and Political Science, Diponegoro University that has supported research fund through DIPA research grant 2020. Expression of appreciation is also delivered to informants in city governments and community that have willingness to allocate their time for interviews to share their views and experiences.

\section{References}

[1] I. Pal, J. Von Meding, and C. Klinmalai, "Regional Perspectives on Disaster Resilience and Sustainable Development," in An Interdisciplinary Approach for Disaster Resilience and Sustainability, I. Pal, J. von Meding, S. Shrestha, I. Ahmed, and T. Gajendran, Eds. Singapore: Springer, 2020, pp. 3-20.

[2] C. Wilson, "Illiberal democracy and violent conflict in contemporary Indonesia," Democratization, vol. 22, no. 7, pp. 1317-1337, 2015.

[3] L. Cheshire, "Know your neighbours': disaster resilience and the normative practices of neighbouring in an urban context," Environ. Plan. A, vol. 47, no. 5, pp. 1081-1099, 2015.

[4] M. A. Burayidi, A. Allen, J. Twigg, and C. Wamsler, The Routledge Handbook of Urban Resilience. Routledge, 2019.

[5] M. Montenegro, "Urban resilience," Landsc. Archit. Mag., vol. 100, no. 7, pp. 68-77, 2010.

[6] P. J. G. Ribeiro and L. A. P. J. Gonçalves, "Urban resilience: A conceptual framework," Sustain. Cities Soc., vol. 50, p. 101625, 2019.

[7] S. Caputo, M. Caserio, R. Coles, L. Jankovic, and M. R. Gaterell, "Urban resilience: two diverging interpretations," J. Urban. Int. Res. Placemaking Urban Sustain., vol. 8, no. 3, pp. 222 $240,2015$.

[8] S. Meerow and J. P. Newell, "Urban resilience for whom, what, when, where, and why?," Urban Geogr., vol. 40, no. 3, pp. 309-329, 2019.

[9] L. Khirfan and H. El-Shayeb, "Urban climate resilience through socio-ecological planning: a case study in Charlottetown, Prince Edward Island," J. Urban. Int. Res. Placemaking Urban Sustain., vol. 13, no. 2, pp. 187-212, 2020.

[10] T. J. Campanella, "Urban resilience and the recovery of New Orleans," J. Am. Plan. Assoc., vol. 72 , no. 2, pp. 141-146, 2006.

[11] J. Coaffee, Terrorism, risk and the global city: Towards urban resilience. Routledge, 2016.

[12] A. Ratanawaraha, "Inequality, Fragility, and Resilience in Bangkok."

[13] S. L. Cutter, K. D. Ash, and C. T. Emrich, "Urban-rural differences in disaster resilience," Ann. Am. Assoc. Geogr., vol. 106, no. 6, pp. 1236-1252, 2016. 